\title{
Cooperative Evolutionary Game and Applications in Construction Supplier Tendency
}

\author{
Qianqian Shi $(\mathbb{D}$, Jianbo Zhu $(\mathbb{D}$, and Qian Li $\mathbb{D}$ \\ School of Management and Engineering, Nanjing University, Nanjing 210093, China \\ Correspondence should be addressed to Qian Li; qianli@nju.edu.cn
}

Received 24 July 2017; Accepted 11 December 2017; Published 21 January 2018

Academic Editor: Pietro De Lellis

Copyright (c) 2018 Qianqian Shi et al. This is an open access article distributed under the Creative Commons Attribution License, which permits unrestricted use, distribution, and reproduction in any medium, provided the original work is properly cited.

\begin{abstract}
Major construction projects have a great influence on the national economy and society, wherein cooperative relationship between construction suppliers plays an increasingly significant role in the overall supply chain system. However, the relationships between suppliers are noncontractual, multistage, dynamic, and complicated. To gain a deeper insight into the suppliers' cooperative relationships, an evolutionary game model is developed to explore the cooperation tendency of multisuppliers. A replicator dynamic system is further formulated to investigate the evolutionary stable strategies of multisuppliers. Then, fourteen "when-then" type scenarios are concluded and classified into six different evolutionary tracks. Meanwhile, the critical influencing factors are identified. The results show that the suppliers' production capacity, owner-supplier contract, and the owner's incentive mechanism influence the cooperation tendency of suppliers directly. The managerial implications contribute to insightful references for a more stable cooperative relationship between the owner and suppliers.
\end{abstract}

\section{Introduction}

Critical infrastructure is an asset or system which is essential for the maintenance of vital societal and economic functions [1-3], areas concerned including the facilities for water supply, security services, power system, transportation, and so forth. In essence, major construction project is one of the most important forms of critical infrastructure, such as bridges and highways. If major construction projects fail, the consequences would be enormous in scale, influencing national politics, economy, society, environmental protection, public health system, and national security [2]. Therefore, adequate attention should be placed on the major construction projects.

However, there are still great complexities in the construction of major construction projects, especially those manifested by complex technology, high duration, and quality requirement. For example, in the construction of Hong KongZhuhai-Macao Bridge, 425,000 million tons of steel needs to be manufactured within three years, which has brought a great challenge. Instead of traditional onsite manufacturing, prefabrication is adopted in this project. Prefabrication is a construction operation approach that aims to produce assemblies and components of the project in a specialized factory or other manufacturing sites in a standardized and controlled process, which transfers project work activities from the site to a safer and more efficient off-site location. Efficient application of prefabrication enables the major construction projects to attain higher productivity, improved quality, and significant time-cost savings [4].

Moreover, a distributed supply chain has been formed due to the production mode of standardization and modularization, mass customization of prefabricated components in a specialized factory, and assembly at the construction site. For instance, in the project of Hong Kong-Zhuhai-Macao Bridge, the production processes of the steel box girders are divided into three parts, namely, plate unit manufacturing, beam segment assembly, and in-site connection. Plate units, a basic component of a steel box girder, are produced in the off-site multisuppliers' factories that are located in Shanhaiguan, Wuhan, Nantong, and Yangzhou, respectively. When the modular production is finished, units will be transported to the Zhongshan base of each supplier for the next assembling process. This distributed supply chain adopts modular prefabricated production and large segment assembly near the construction site, rather than traditional 
production mode, which can save transportation cost, ensure transportation safety, and minimize site waste $[5,6]$.

Although the use of prefabrication is quite favorable, only a few (over 37\%) construction suppliers would choose modularization and prefabrication at higher levels [7]. Previous researches have explored several success factors for high levels of prefabrication [8], in which the cooperative relationship has been highlighted to affect prefabrication performance especially [9]. The research shows that cooperation among prefabrication suppliers allows them to obtain additional resource with less investment in the distributed supply chain $[5,8]$. Therefore, the issue of stable cooperation tendency between prefabrication suppliers has become highly relevant for both academics and practitioners [10].

This paper focuses on the cooperation tendency among suppliers who adopt prefabrication in major construction projects (hereinafter referred to as supplier). There are several traits of suppliers' relationships. Firstly, their relationships are different from owner-contractor and contractorsubcontractor relationships that have been analyzed earlier [11]. The difference is that the relationships between suppliers are noncontractual relationships, while general relationships in project networks are contractual ones [12]. Secondly, the relationships between suppliers are likely to be weak [13]. Besides, it is difficult to judge whether the major construction projects as complex systems can form cooperative relationships or competitive relationships between suppliers, due to the risks arising from asymmetric information, shortsightedness, self-interest, and so on [14]. Thirdly, the stability of cooperative relationships between suppliers is dynamical [14]. It is necessary to place an emphasis on the multistagegame cooperation rather than the one-stage-game cooperation [15].

Therefore, this paper aims to gain a deeper insight into the issues about the suppliers' noncontractual cooperative relationships in major construction projects when taking their traits into consideration. In order to identify the relevant factors that may influence the stability of the cooperative relationship between suppliers and to explore the cooperation tendency of this relationship, the evolutionary game theory is adopted in this paper to cast new light into this issue. The remaining part of this paper is organized as follows. Section 2 presents a literature review on current researches. In Section 3, a dynamical game model will be developed, where "when-then" type scenarios are investigated and several critical influencing factors are analyzed as well. An application is conducted to verify the evolutionary stable strategy (ESS) in Section 4. Finally, conclusions and future research directions are given in Section 5.

\section{Literature Review}

Competition among construction project participants has been considered as an effective tool to improve efficiency, reduce production cost, and maximize social welfare [16]. Then, a number of researches around competition in construction projects have been done in academia [17]. Yet, the demand for cooperation of high level among project participants is gradually increasing due to the increased uncertainty, complexity, technical difficulty, quality requirement, intensive knowledge, and time pressure [18]. Therefore, fostering cooperation among project participants has become a large concern $[19,20]$.

Although cooperation is regarded as a one-dimensional construct in some studies, more and more scholars demonstrate that cooperation is a multidimensional concept [21]. Some of them classify cooperation into two forms based on different attitudes [20] - namely, obligatory cooperation and voluntary cooperation; others divide cooperation into three categories based on the structure of the construction supply chain [22]—namely, vertical, horizontal, or lateral-while there are also some scholars who deal with cooperation relationship from the perspective of contract: noncontractual cooperation and contractual cooperation [12].

Cruijssen et al. [23] pointed out that most researches focused on both vertical cooperation in supply chains and lateral cooperation in supply networks, while Sariola and Martinsuo [12] considered that construction-specific researches concentrated on the contractual relationships but ignored the noncontractual relationships in the project network. For instance, many scholars sought the factors that affect cooperation and tried to give suggestions for promoting vertical and contractual cooperation relationships. To be more specific, Bemelmans et al. [24] carried out the research on contractor-supplier contractual and vertical relationships. Cheung et al. [25] identified the cooperative and aggressive drivers in construction contracting and then provided useful suggestions to facilitate an environment in fostering cooperative contracting. Paulraj et al. [26] proposed an interorganizational communication as a relational competency to enhance the buyer-supplier relationship. Kim and Netessine [27] presented their ideas that expected margin commitment (EMC) can promote cooperation between manufacturers and suppliers. Quanji et al. [20] dimensionalized contractual governance into control, coordination, and adaptation and demonstrated the contractual governance effects on cooperation in construction projects.

The cooperation relationships between suppliers which this paper concentrates on belong to horizontal and noncontractual cooperation. Nevertheless, Zineldin and Bredenlöw [28] found that horizontal cooperation often failed for some reasons, and more and more scholars emphasized the importance and advantages of horizontal cooperation. For example, Jiang et al. [29] highlighted that local suppliers' cooperation may be an effective way for improving labor conditions. Choi et al. [30] divided supplier-supplier relationships into three archetypes: competitive, cooperative, and coopetitive. $\mathrm{He}$ considered that suppliers can work closely together and exchange ideas. Furthermore, a line of researches studying horizontal cooperation relationship are carried out from different standpoints. Wu et al. [31] studied coopetitive suppliersupplier relationships by using theory building through eight case studies, and they illustrated the effect of buyers' role in managing supplier-supplier coopetition to improve supplier performance. Saad et al. [32] investigated that more and more construction practitioners used the supply chain management methods to establish long-term strategic cooperation relationships, through the empirical analysis of the British 
construction industry. Hong and Hartley [33] explored three approaches that the buyers can adopt to manage suppliersupplier interface. Lazzarini et al. [34] demonstrated that the interaction between buyer-supplier (vertical) and suppliersupplier (horizontal) alliances depended on the level of technological uncertainty.

Note that existing studies confirm that cooperative relationships are not easily to be established [35]. Previous studies have already realized the importance of cooperative relationships and explored several critical success factors in implementation of cooperation [36]. Nevertheless, the issues, such as under what conditions the cooperation can be formed ("when-then" type scenarios), what the trajectory of the dynamic change is in the relationships between suppliers, and how the stability of the cooperative relationship between suppliers is, are also great concerns for both scholars and practitioners. Although the relevant research has emerged [37-39], the researches about these topics are rare, especially in construction industry.

The evolutionary game theory is a theory that combines game theory with biodynamic evolution process. It carries out economic system researches and is mainly used to analyze the balance point and stability of the players' strategies [40]. In general, the players' interaction behaviors directly affect their payoff. Besides, the players are implied to be bounded rational; therefore, they cannot find the optimal strategy from the beginning. Instead, they would attempt to improve their selections through continuous learning. In fact, the key of evolutionary game theory lies in finding the frequencies of strategies adjusted and adopted in the population as an evaluation criterion in making decisions during the evolutionary game process [15]. Therefore, the evolutionary game theory is a widely utilized tool to analyze the competition and cooperation between rational decision makers, which does not need to consider the effect of the contract [15]. For example, $\mathrm{Xu}$ et al. [14] applied stochastic evolutionary game theory to analyze the stability of cooperation among members in a strategic alliance against external opportunism. Liu et al. [41] analyzed investors' opportunistic behavior and the impact of government supervision during the operational period in PPP projects with the evolutionary game theory. Ji et al. [15] adopted evolutionary game theory to evaluate the green purchasing relationships for the manufacturing industry.

Considering a huge demand in major construction projects and the situation, the owner delegates multiple suppliers to provide the same products, and the suppliers are always bounded rational because of information asymmetry and the limitation of humans' cognition. On the other hand, in the construction supply chain, the relationship between the suppliers is noncontractual cooperation or noncooperation, so it is natural to apply the evolutionary game theory to explore the game process of continuous learning and the changing of cooperation tendency among multistakeholders (suppliers). Feng et al. [42] investigated the influence of benefit distribution mechanism and incentive and penalty mechanism on the cooperative mechanism of prefabricated producers. However, the drawbacks are that they considered producers' cooperation relationship as contractual relationship and distributed excess returns, which is hardly to realize in competitive producers. And they mainly focused on the basis of penalties and incentive mechanisms from suppliers' perspective only. Due to the deficiency, we will develop an evolutionary game model based on an empirical research and with application on an actual major construction project. The novelty of our model is that the suppliers' production capacity, owner-supplier contract, and incentive mechanism are all taken into account. Therefore, based on the researches above and the evolutionary game theory, the paper investigates the evolutionary track of the relationships between suppliers, concludes "when-then" type scenarios, and explores the critical influencing factors and critical factors' impact on the stability of cooperative relationship. The results will provide suggestions for the owners of the major construction projects, who are willing to promote cooperation among suppliers.

\section{An Evolutionary Game Model for Cooperation Mechanism}

3.1. Model Description. The paper focuses on the cooperative relationships between suppliers who provide key components for major construction projects. Due to the characteristics of huge technical difficulties, quality requirement, intensive knowledge, and tight duration, the suppliers tend to cooperate with other suppliers, such as equipment sharing, resource sharing, technology sharing, and even R\&D (research and development), in order to meet the requirements and reduce production costs. However, spillover effect will come up when heterogeneous suppliers cooperate mutually, which means the core technology and knowledge would be learned by competitors in the same industry. Therefore, the suppliers are likely to choose noncooperative strategies. In addition, as the suppliers are generally bounded rational, it is difficult for the suppliers who are constrained by their own cognitive level and inferential capability to make the optimal decision for the first time. And they may adjust their strategies to gain higher profits based on observation and learning during each delivery cycle. Thus, in order to comprehensively explore the relationship between suppliers, an evolutionary game model is developed.

The model assumes that there are two kinds of suppliers in the game: supplier I and supplier II, who provide the same products to the owner. And incentive contracts are signed between each supplier and the owner in order to, respectively, specify the order quantities, unit prices, and unit incentive prices of different products. The notations are as follows:

$k$ : index for different kinds of products; $k=$ $1,2,3, \ldots, l$

$d_{1}^{k}, d_{2}^{k}$ : the order quantity of product $k$ of supplier I and supplier II, respectively

$m^{k}$ : the unit price of product $k$ paid by the owner for both suppliers

$n^{k}$ : the unit incentive price of product $k$ paid by the owner for both suppliers 
TABLE 1: Payoff matrix between suppliers.

\begin{tabular}{llcc}
\hline \multirow{2}{*}{ Parties in the game } & \multicolumn{2}{c}{ Supplier II } \\
& & Cooperation & Noncooperation \\
\hline \multirow{2}{*}{ Supplier I } & Cooperation & $\pi_{c c}^{1}, \pi_{c c}^{2}$ & $\pi_{c n}^{1}, \pi_{c n}^{2}$ \\
& Noncooperation & $\pi_{n c}^{1}, \pi_{n c}^{2}$ & $\pi_{n n}^{1}, \pi_{n n}^{2}$ \\
\hline
\end{tabular}

$\rho^{k}$ : the probability of succeeding in improving the quality of product $k$ and reducing production time of product $k$ when both suppliers choose to cooperate with each other; $0<\rho^{k}<1$

$\beta^{k}$ : the probability of succeeding in improving the quality of product $k$ and reducing production time of product $k$ when only one supplier chooses to cooperate; apparently, $\beta^{k}<\rho^{k}$ and $0<\beta^{k}<1$

$c_{1}^{k}, c_{2}^{k}$ : the unit production cost of product $k$ of supplier I and supplier II, respectively

$\gamma_{1}^{k}, \gamma_{2}^{k}$ : the coefficient of spillover effect of product $k$ for supplier I and supplier II, respectively, assumed as cost externality generated from cooperation

$f_{1}^{k}, f_{2}^{k}$ : the cooperation cost of product $k$ of supplier I and supplier II, respectively, such as new equipment purchase cost, expert consultation fee, and innovation cost.

3.2. Model Establishment and Solution. Based on the descriptions above, the payoff matrix between suppliers can be established, as shown in Table 1, where the payoff functions of supplier I are as follows:

$$
\begin{aligned}
& \pi_{c c}^{1}=d_{1}^{k}\left(m^{k}+\rho^{k} n^{k}\right)-\frac{1}{1+\gamma_{1}^{k}} d_{1}^{k} c_{1}^{k}-f_{1}^{k}, \\
& \pi_{c n}^{1}=d_{1}^{k}\left(m^{k}+\beta^{k} n^{k}\right)-\frac{1}{1+\gamma_{1}^{k}} d_{1}^{k} c_{1}^{k}-f_{1}^{k}, \\
& \pi_{n c}^{1}=d_{1}^{k}\left(m^{k}+\beta^{k} n^{k}\right)-d_{1}^{k} c_{1}^{k}, \\
& \pi_{n n}^{1}=d_{1}^{k} m^{k}-d_{1}^{k} c_{1}^{k}
\end{aligned}
$$

and the payoff functions of supplier II are as follows:

$$
\begin{aligned}
& \pi_{c c}^{2}=d_{2}^{k}\left(m^{k}+\rho^{k} n^{k}\right)-\frac{1}{1+\gamma_{2}^{k}} d_{2}^{k} c_{2}^{k}-f_{2}^{k}, \\
& \pi_{c n}^{2}=d_{2}^{k}\left(m^{k}+\beta^{k} n^{k}\right)-d_{2}^{k} c_{2}^{k}, \\
& \pi_{n c}^{2}=d_{2}^{k}\left(m^{k}+\beta^{k} n^{k}\right)-\frac{1}{1+\gamma_{2}^{k}} d_{2}^{k} c_{2}^{k}-f_{2}^{k}, \\
& \pi_{n n}^{2}=d_{2}^{k} m^{k}-d_{2}^{k} c_{2}^{k} .
\end{aligned}
$$

In the game model, the two suppliers have different strategies and payoffs. Assume that $x$ represents the possibility of supplier I taking a cooperative strategy, and then the possibility of taking the noncooperative strategy is $1-x$. Similarly, $y$ represents the possibility of supplier II taking a cooperative strategy, and then the possibility of taking the noncooperative strategy is $1-y$. Thus, $(x, y) \in[0,1] \times$ $[0,1]$. When the expected payoffs of the two players are lower than their average expected payoffs, a player may adjust his strategies during the game process. So, $x$ and $y$ are changing [15].

According to Table 1, let $E_{11}$ and $E_{12}$ be the expected payoffs of supplier I who takes different strategies (cooperation or noncooperation, resp.), and then, $E_{11}$ and $E_{12}$ are as follows:

$$
\begin{aligned}
E_{11}= & y \pi_{c c}^{1}+(1-y) \pi_{c n}^{1} \\
= & d_{1}^{k} m^{k}-\frac{1}{1+\gamma_{1}^{k}} d_{1}^{k} c_{1}^{k}-f_{1}^{k}+y d_{1}^{k} \rho^{k} n^{k} \\
& +(1-y) d_{1}^{k} \beta^{k} n^{k}, \\
E_{12}= & y \pi_{n c}^{1}+(1-y) \pi_{n n}^{1}=d_{1}^{k} m^{k}-d_{1}^{k} c_{1}^{k}+y d_{1}^{k} \beta^{k} n^{k} .
\end{aligned}
$$

The average expected payoff of supplier I is

$$
\begin{aligned}
\overline{E_{1}}= & x E_{11}+(1-x) E_{12} \\
= & d_{1}^{k} m^{k}-x\left(\frac{1}{1+\gamma_{1}^{k}} d_{1}^{k} c_{1}^{k}+f_{1}^{k}-y d_{1}^{k} \rho^{k} n^{k}\right) \\
& -(1-x) d_{1}^{k} c_{1}^{k}+(x+y-2 x y) d_{1}^{k} \beta^{k} n^{k} .
\end{aligned}
$$

Similarly, let $E_{21}$ and $E_{22}$ be the expected payoffs of supplier II who takes different strategies (cooperation or noncooperation, resp.), and then, $E_{21}$ and $E_{22}$ are as follows:

$$
\begin{aligned}
E_{21}= & d_{2}^{k} m^{k}-\frac{1}{1+\gamma_{2}^{k}} d_{2}^{k} c_{2}^{k}-f_{2}^{k}+x d_{2}^{k} \rho^{k} n^{k} \\
& +(1-x) d_{2}^{k} \beta^{k} n^{k}, \\
E_{22}= & d_{2}^{k} m^{k}-d_{2}^{k} c_{2}^{k}+x d_{2}^{k} \beta^{k} n^{k} .
\end{aligned}
$$

The average expected payoff of supplier II is

$$
\begin{aligned}
\overline{E_{2}}= & y E_{21}+(1-y) E_{22} \\
= & d_{2}^{k} m^{k}-y\left(\frac{1}{1+\gamma_{2}^{k}} d_{2}^{k} c_{2}^{k}+f_{2}^{k}-x d_{2}^{k} \rho^{k} n^{k}\right) \\
& -(1-y) d_{2}^{k} c_{2}^{k}+(x+y-2 x y) d_{2}^{k} \beta^{k} n^{k} .
\end{aligned}
$$

In a replicator dynamic system, the greatly significant growth rate of a strategy can reflect the evolutionary direction. It generally depends on the speed at which the players learn and imitate. Based on the research of Friedman [43] and Xiao and Yu [44], the growth rate of a strategy selected by the suppliers should be equal to its expected payoff minus the average expected payoff. Therefore, the replicator dynamic 
equations of supplier I and supplier II are as follows, respectively:

$$
\begin{aligned}
& \frac{d x}{d t}=x(1-x)\left[y\left(\rho^{k}-2 \beta^{k}\right) d_{1}^{k} n^{k}+\frac{\gamma_{1}^{k}}{1+\gamma_{1}^{k}} d_{1}^{k} c_{1}^{k}-f_{1}^{k}\right. \\
& \left.\quad+d_{1}^{k} \beta^{k} n^{k}\right], \\
& \frac{d y}{d t}=y(1-y)\left[x\left(\rho^{k}-2 \beta^{k}\right) d_{2}^{k} n^{k}+\frac{\gamma_{2}^{k}}{1+\gamma_{2}^{k}} d_{2}^{k} c_{2}^{k}-f_{2}^{k}\right. \\
& \left.+d_{2}^{k} \beta^{k} n^{k}\right] .
\end{aligned}
$$

According to the stability theorem of differential equations, the equilibrium point of the replicator dynamic equations presented by (7) should satisfy $d x / d t=0, d y / d t=0$, and $(x, y) \in[0,1] \times[0,1]$.

Apparently, $O(0,0), A(0,1), B(1,0)$, and $C(1,1)$ are the four fixed equilibrium points. For convenience, let $x^{*}$

$J$

$=\left[\begin{array}{c}(1-2 x)\left[y\left(\rho^{k}-2 \beta^{k}\right) d_{1}^{k} n^{k}+\frac{\gamma_{1}^{k}}{1+\gamma_{1}^{k}} d_{1}^{k} c_{1}^{k}-f_{1}^{k}+d_{1}^{k} \beta^{k} n^{k}\right] \\ y(1-y)\left(\rho^{k}-2 \beta^{k}\right) d_{2}^{k} n^{k}\end{array}\right.$

The determinant (det) and the trace (tr) of $J$ are as follows:

$$
\begin{aligned}
& \operatorname{det} J=(1-2 x)(1-2 y) \\
& \cdot\left[y\left(\rho^{k}-2 \beta^{k}\right) d_{1}^{k} n^{k}+\frac{\gamma_{1}^{k} d_{1}^{k} c_{1}^{k}}{\left(1+\gamma_{1}^{k}\right)}-f_{1}^{k}+d_{1}^{k} \beta^{k} n^{k}\right] \\
& \cdot\left[x\left(\rho^{k}-2 \beta^{k}\right) d_{2}^{k} n^{k}+\frac{\gamma_{2}^{k} d_{2}^{k} c_{2}^{k}}{\left(1+\gamma_{2}^{k}\right)}-f_{2}^{k}+d_{2}^{k} \beta^{k} n^{k}\right] \\
& -x(1-x)\left(\rho^{k}-2 \beta^{k}\right) d_{1}^{k} n^{k} y(1-y)\left(\rho^{k}-2 \beta^{k}\right) \\
& \cdot d_{2}^{k} n^{k}, \\
& \operatorname{tr} J=(1-2 x) \\
& \cdot\left[y\left(\rho^{k}-2 \beta^{k}\right) d_{1}^{k} n^{k}+\frac{\gamma_{1}^{k} d_{1}^{k} c_{1}^{k}}{\left(1+\gamma_{1}^{k}\right)}-f_{1}^{k}+d_{1}^{k} \beta^{k} n^{k}\right] \\
& \quad+(1-2 y) \\
& \cdot\left[x\left(\rho^{k}-2 \beta^{k}\right) d_{2}^{k} n^{k}+\frac{\gamma_{2}^{k} d_{2}^{k} c_{2}^{k}}{\left(1+\gamma_{2}^{k}\right)}-f_{2}^{k}+d_{2}^{k} \beta^{k} n^{k}\right] .
\end{aligned}
$$

The stability conditions of the replicator dynamic equations will be divided into fourteen scenarios. The fourteen scenarios can be classified into the following six kinds of $=\left[\gamma_{2}^{k} d_{2}^{k} c_{2}^{k}+\left(1+\gamma_{2}^{k}\right)\left(d_{2}^{k} \beta^{k} n^{k}-f_{2}^{k}\right)\right] /\left[\left(1+\gamma_{2}^{k}\right)\left(2 \beta^{k}-\rho^{k}\right) d_{2}^{k} n^{k}\right]$, $y^{*}=\left[\gamma_{1}^{k} d_{1}^{k} c_{1}^{k}+\left(1+\gamma_{1}^{k}\right)\left(d_{1}^{k} \beta^{k} n^{k}-f_{1}^{k}\right)\right] /\left[\left(1+\gamma_{1}^{k}\right)\left(2 \beta^{k}-\right.\right.$ $\left.\left.\rho^{k}\right) d_{1}^{k} n^{k}\right], r_{1}=f_{1}^{k}-\gamma_{1}^{k} d_{1}^{k} c_{1}^{k} /\left(1+\gamma_{1}^{k}\right), r_{2}=f_{2}^{k}-\gamma_{2}^{k} d_{2}^{k} c_{2}^{k} /(1+$ $\left.\gamma_{2}^{k}\right), r_{11}=\left(\rho^{k}-\beta^{k}\right) d_{1}^{k} n^{k}, r_{12}=\beta^{k} d_{1}^{k} n^{k}, r_{21}=\left(\rho^{k}-\right.$ $\left.\beta^{k}\right) d_{2}^{k} n^{k}$, and $r_{22}=\beta^{k} d_{2}^{k} n^{k}$; then, $D\left(x^{*}, y^{*}\right)$ is also an equilibrium point when meeting the following conditions: (1) when $2 \beta^{k}-\rho^{k} \geq 0, r_{11} \leq r_{1} \leq r_{12}$, and $r_{21} \leq r_{2} \leq r_{22}$, or (2) when $2 \beta^{k}-\rho^{k}<0, r_{12}<r_{1}<r_{11}$, and $r_{22}<r_{2}<r_{21}$.

Here, $r_{1}, r_{2}$ represent the extra costs due to cooperation of supplier I and supplier II, respectively; $r_{11}, r_{21}$ represent the margins between the expected incentive incomes of both sides choosing to cooperate and of only one side choosing to cooperate of supplier I and supplier II, respectively; and $r_{12}, r_{22}$ represent the expected incentive incomes of only one side choosing to cooperate of supplier I and supplier II, respectively.

3.3. Model Discussion. Based on the research proposed by Friedman [43], the stability condition at the equilibrium points can be obtained by the application of Jacobian matrix. Thus, the Jacobian matrix of the differential equation system made of (7) is diagrams on the dynamic evolution of the equilibrium points (see Figure 1).

Category 1. When $r_{1} \geq \max \left(r_{11}, r_{12}\right)$ and $r_{2} \geq \max \left(r_{21}, r_{22}\right)$, or when $2 \beta^{k}-\rho^{k}<0, r_{1} \geq \max \left(r_{11}, r_{12}\right)$, and $r_{22}<r_{2}<r_{21}$, or when $2 \beta^{k}-\rho^{k}<0, r_{12}<r_{1}<r_{11}$, and $r_{2} \geq \max \left(r_{21}, r_{22}\right)$, that is, when compared to the margin between the expected incentive incomes of both sides choosing to cooperate and of only one side choosing to cooperate, as well as the expected incentive income of only one side choosing to cooperate, the extra costs due to cooperation of both supplier I and supplier II $\left(r_{1}, r_{2}\right)$ are high enough, at which point the dynamic system is eventually evolved to choose noncooperation strategy by both suppliers. $O(0,0)$ is the only stable point of the system.

Category 2. When $r_{1} \geq \max \left(r_{11}, r_{12}\right)$ and $r_{2} \leq \max \left(r_{21}, r_{22}\right)$, or when $2 \beta^{k}-\rho^{k} \geq 0, r_{1} \geq \max \left(r_{11}, r_{12}\right)$, and $r_{21}<r_{2}<r_{22}$, or when $2 \beta^{k}-\rho^{k} \geq 0, r_{11}<r_{1}<r_{12}$, and $r_{2} \leq \max \left(r_{21}, r_{22}\right)$, that is, when compared to the margin between the expected incentive incomes of both sides choosing to cooperate and of only one side choosing to cooperate, as well as the expected incentive income of only one side choosing to cooperate, the extra cost due to cooperation of supplier I $\left(r_{1}\right)$ is high enough, while the extra cost due to cooperation of supplier II $\left(r_{2}\right)$ is 

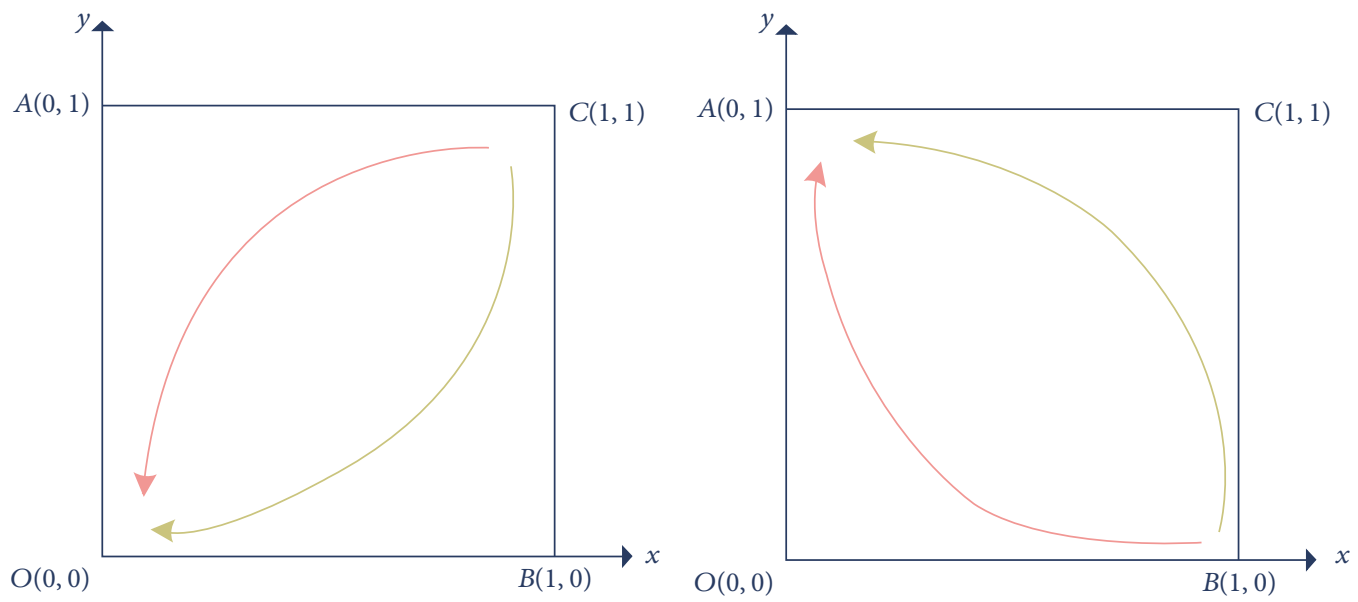

Category 1

Category 2
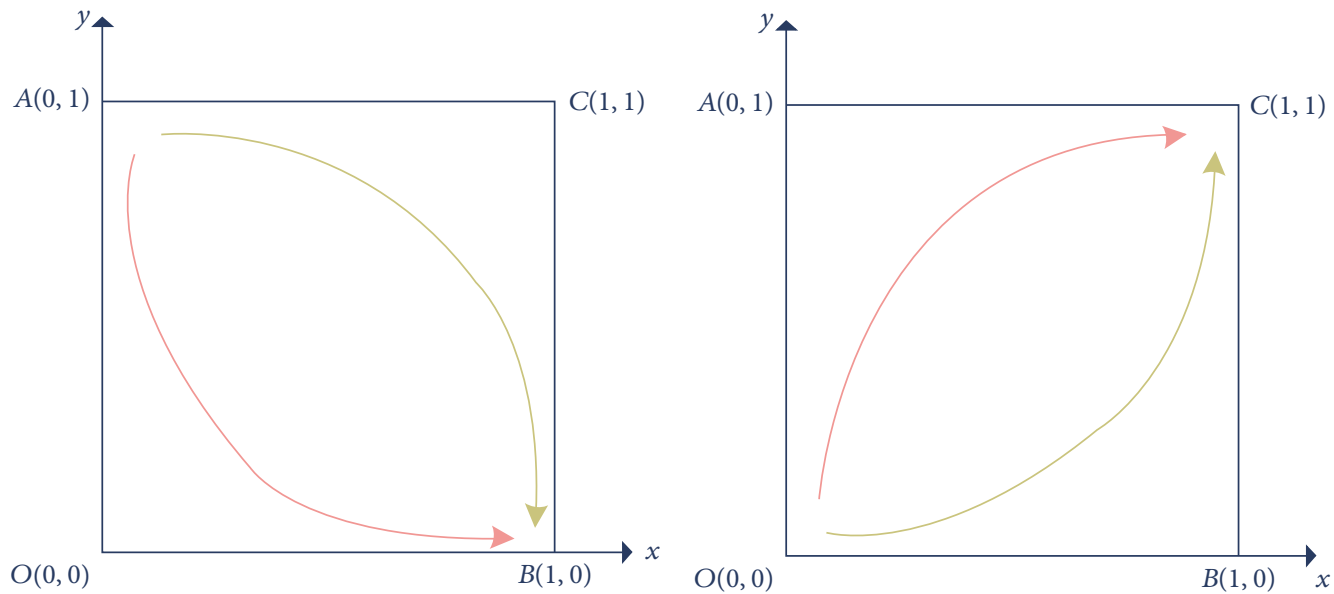

Category 3

Category 4
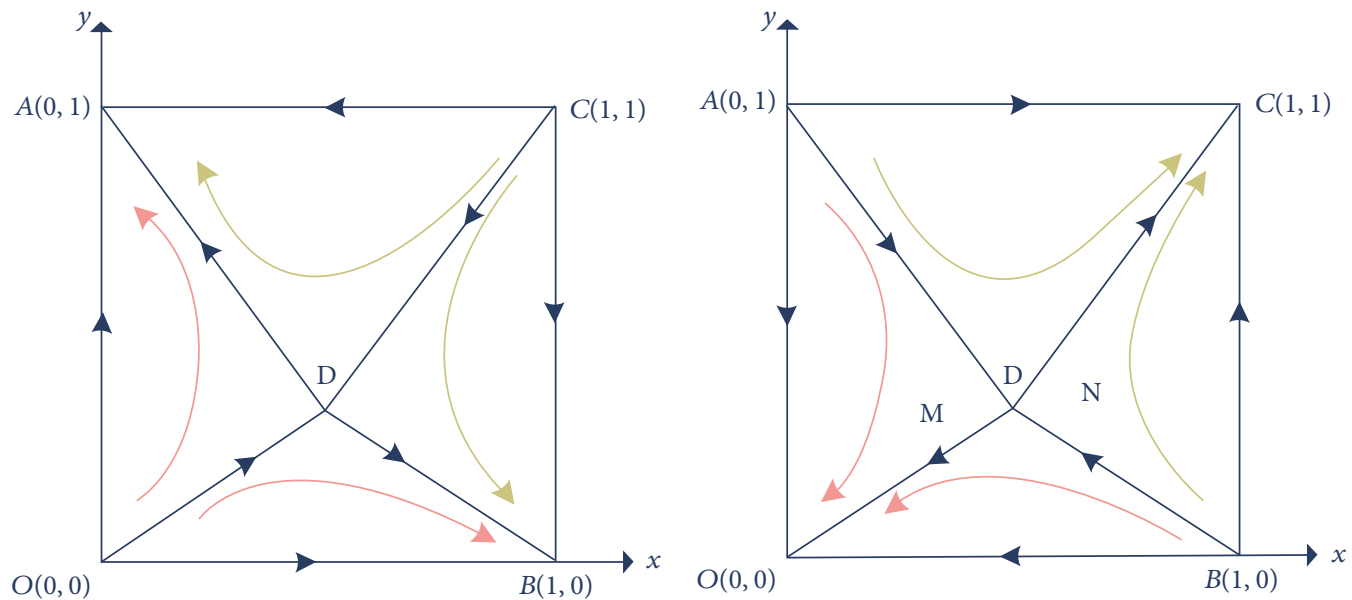

Category 5

Category 6

FIGURE 1: Diagrams on the dynamic evolution of the equilibrium points. 
low enough, at which point the dynamic system is eventually evolved to choose noncooperation strategy by supplier I and choose cooperation strategy by supplier II. $A(0,1)$ is the only stable point of the system.

Category 3. When $r_{1} \leq \max \left(r_{11}, r_{12}\right)$ and $r_{2} \geq \max \left(r_{21}, r_{22}\right)$, or when $2 \beta^{k}-\rho^{k} \geq 0, r_{11} \leq r_{1} \leq r_{12}$, and $r_{2} \geq \max \left(r_{21}, r_{22}\right)$, or when $2 \beta^{k}-\rho^{k} \geq 0, r_{1} \leq \max \left(r_{11}, r_{12}\right)$, and $r_{21} \leq r_{2} \leq r_{22}$, that is, when compared to the margin between the expected incentive incomes of both sides choosing to cooperate and of only one side choosing to cooperate, as well as the expected incentive income of only one side choosing to cooperate, the extra cost due to cooperation of supplier I $\left(r_{1}\right)$ is low enough, while the extra cost due to cooperation of supplier II $\left(r_{2}\right)$ is high enough, at which point the dynamic system is eventually evolved to choose cooperation strategy by supplier I and choose noncooperation strategy by supplier II. $B(1,0)$ is the only stable point of the system.

Category 4. When $r_{1} \leq \max \left(r_{11}, r_{12}\right)$ and $r_{2} \leq \max \left(r_{21}, r_{22}\right)$, or when $2 \beta^{k}-\rho^{k}<0, r_{12}<r_{1}<r_{11}$, and $r_{2} \leq \max \left(r_{21}, r_{22}\right)$, or when $2 \beta^{k}-\rho^{k}<0, r_{1} \leq \max \left(r_{11}, r_{12}\right)$, and $r_{22}<r_{2}<r_{21}$, that is, when compared to the margin between the expected incentive incomes of both sides choosing to cooperate and of only one side choosing to cooperate, as well as the expected incentive income of only one side choosing to cooperate, the extra costs due to cooperation of both supplier I and supplier II $\left(r_{1}, r_{2}\right)$ are low enough, at which point the dynamic system is eventually evolved to choose cooperation strategy by both suppliers. $C(1,1)$ is the only stable point of the system.

Category 5. When $2 \beta^{k}-\rho^{k} \geq 0, r_{11} \leq r_{1} \leq r_{12}$, and $r_{21} \leq r_{2} \leq$ $r_{22}$, that is, when the probability of succeeding in improving the product quality and reducing production time when only one supplier chooses to cooperate is higher than half of the probability when both suppliers choose to cooperate and the extra costs due to cooperation of both supplier I and supplier II $\left(r_{1}, r_{2}\right)$ are higher than the margin between the expected incentive incomes of both sides choosing to cooperate and of only one side choosing to cooperate of each supplier, respectively, and lower than the expected incentive income of only one side choosing to cooperate of each supplier, respectively, at which point the dynamic system is eventually evolved to choose cooperation strategy by one supplier and only one supplier chooses noncooperation strategy by the other supplier. $A(0,1)$ and $B(1,0)$ are the stable points of the system.

Category 6. When $2 \beta^{k}-\rho^{k}<0, r_{12}<r_{1}<r_{11}$, and $r_{22}<r_{2}<$ $r_{21}$, that is, when the probability of succeeding in improving the product quality and reducing production time when only one supplier chooses to cooperate is lower than half of the probability when both suppliers choose to cooperate and the extra costs due to cooperation of both supplier I and supplier II $\left(r_{1}, r_{2}\right)$ are lower than the margin between the expected incentive incomes of both sides choosing to cooperate and of only one side choosing to cooperate of each supplier, respectively, and higher than the expected incentive income of only one side choosing to cooperate of each supplier, respectively, at which point the dynamic system is eventually evolved to either choose cooperation strategy by both suppliers or choose noncooperation strategy by both suppliers. $O(0,0)$ and $C(1,1)$ are the stable points of the system.

3.4. Model Analysis. Developing the cooperative relationship between suppliers not only has a better impact on the owner's profit but also can promote the development of the industry. Then, the focus of the paper is how to promote the suppliers to choose cooperation strategy, which is to make the dynamic system converge to $C(1,1)$. Therefore, a further analysis on category 4 and category 6 needs to be carried out. In category 4 , it is clear that when the conditions are met, $C(1,1)$ will be the only stable point of the system. Therefore, the following analysis will focus on category 6 .

In category 6 , whether the system eventually converges to $O(0,0)$ or $C(1,1)$ depends on the initial state of the system. When the initial state falls into the area $M$ (i.e., quadrangle $O A D B)$ in the diagram, the system will converge toward $O(0,0)$, which means that the suppliers both choose noncooperation strategy; when the initial state falls into the area $N$ (i.e., quadrangle $C A D B$ ) in the diagram, the system will converge toward $C(1,1)$, which means that the suppliers both choose cooperation strategy. The selection of strategy depends on the size of the areas $M, N$.

The size of area $N$ is

$$
\begin{aligned}
S_{N}= & -\frac{\left[\gamma_{2}^{k} d_{2}^{k} c_{2}^{k}+\left(1+\gamma_{2}^{k}\right)\left(d_{2}^{k} \beta^{k} n^{k}-f_{2}^{k}\right)\right]}{\left[2\left(1+\gamma_{2}^{k}\right)\left(2 \beta^{k}-\rho^{k}\right) d_{2}^{k} n^{k}\right]} \\
& -\frac{\left[\gamma_{1}^{k} d_{1}^{k} c_{1}^{k}+\left(1+\gamma_{1}^{k}\right)\left(d_{1}^{k} \beta^{k} n^{k}-f_{1}^{k}\right)\right]}{2\left(1+\gamma_{1}^{k}\right)\left(2 \beta^{k}-\rho^{k}\right) d_{1}^{k} n^{k}} .
\end{aligned}
$$
drawn.

From the analysis, some important conclusions can be

Proposition 1. The larger the spillover effect coefficients of product for supplier I and supplier II are, the greater the motivation of cooperation will be, then the higher the probability of cooperation will be.

\section{Confirmation is}

$$
\frac{\partial S_{N}}{\partial \gamma_{1}^{k}}=\frac{d_{1}^{k} c_{1}^{k}}{\left[2\left(1+\gamma_{1}^{k}\right)^{2}\left(\rho^{k}-2 \beta^{k}\right) d_{1}^{k} n^{k}\right]}>0 .
$$

This is because the total production cost of the contract will decrease due to the larger spillover effect coefficient, in which conditions the suppliers are more willing to develop a cooperative relationship.

Further, the second-order partial derivative is obtained:

$$
\frac{\partial^{2} S_{N}}{\partial\left(\gamma_{1}^{k}\right)^{2}}=-\frac{d_{1}^{k} c_{1}^{k}}{\left[2\left(1+\gamma_{1}^{k}\right)^{3}\left(\rho^{k}-2 \beta^{k}\right) d_{1}^{k} n^{k}\right]}<0 .
$$

The confirmation of supplier II is the same as (11) and (12). This means that the probability of cooperation increases with 
the increasing spillover effect coefficient, while the growth trend is decreased gradually.

Proposition 2. The probability of cooperation between suppliers is correlated positively with the order quantity and the unit production cost of product but negatively with the cooperation cost.

\section{Confirmation is}

$$
\begin{aligned}
\frac{\partial S_{N}}{\partial d_{1}^{k}} & =\frac{f_{1}^{k}}{\left[2\left(d_{1}^{k}\right)^{2}\left(\rho^{k}-2 \beta^{k}\right) n^{k}\right]}>0, \\
\frac{\partial S_{N}}{\partial c_{1}^{k}} & =\frac{\gamma_{1}^{k} c_{1}^{k}}{\left[2\left(1+\gamma_{1}^{k}\right)\left(\rho^{k}-2 \beta^{k}\right) d_{1}^{k} n^{k}\right]}>0, \\
\frac{\partial S_{N}}{\partial f_{1}^{k}} & =\frac{1}{\left[2\left(\rho^{k}-2 \beta^{k}\right) d_{1}^{k} n^{k}\right]}<0 .
\end{aligned}
$$

The confirmation of supplier II is the same as (13).

This proposition represents that when the order quantity of the product and the unit production cost of product become larger, the total production cost of the contract will increase, which means that the production risk is higher, and the motivation that each supplier inclines to cooperate with each other to reduce risk costs will become stronger. Under such circumstances, the probability of cooperation will be higher correspondingly. In addition, when the cooperation cost increases, then the higher risk will result in a higher probability of cooperation between suppliers.

Proposition 3. The probability of cooperation has no concern with the unit price of the product paid by the owner for both suppliers $\left(\mathrm{m}^{k}\right)$, while it is positively related to the unit incentive price $\left(n^{k}\right)$ and the probability of succeeding in improving the quality and in reducing production time when both suppliers choose cooperation strategy $\left(\rho^{k}\right)$.

\section{Confirmation is}

$$
\begin{aligned}
\frac{\partial S_{N}}{\partial n^{k}}= & \frac{\left[\gamma_{1}^{k} d_{1}^{k} c_{1}^{k}-\left(1+\gamma_{1}^{k}\right) f_{1}^{k}\right]}{\left[2\left(1+\gamma_{1}^{k}\right)\left(2 \beta^{k}-\rho^{k}\right)\left(n^{k}\right)^{2} d_{1}^{k}\right]} \\
& +\frac{\left[\gamma_{2}^{k} d_{2}^{k} c_{2}^{k}-\left(1+\gamma_{2}^{k}\right) f_{2}^{k}\right]}{\left[2\left(1+\gamma_{2}^{k}\right)\left(2 \beta^{k}-\rho^{k}\right)\left(n^{k}\right)^{2} d_{2}^{k}\right]}>0, \\
\frac{\partial S_{N}}{\partial \rho^{k}}= & \frac{\left[\gamma_{2}^{k} d_{2}^{k} c_{2}^{k}+\left(1+\gamma_{2}^{k}\right)\left(d_{2}^{k} \beta^{k} n^{k}-f_{2}^{k}\right)\right]}{\left[2\left(1+\gamma_{2}^{k}\right)\left(2 \beta^{k}-\rho^{k}\right)^{2} d_{2}^{k} n^{k}\right]}>0 .
\end{aligned}
$$

The conclusion is in accordance with intuition. The higher the incentive intensity obtained from the owner and the higher the probability of success when both suppliers cooperate, the higher the profit the suppliers will obtain. Therefore, the suppliers will be more willing to choose cooperation strategy.
Proposition 4. When $r_{11}+r_{12}>2 r_{1}$ and $r_{21}+r_{22}>2 r_{2}$, the probability of cooperation will be correlated positively with the probability of succeeding in improving the quality and in reducing production time when only one supplier chooses a cooperation strategy $\left(\beta^{k}\right)$; but when $r_{11}+r_{12}<2 r_{1}$ and $r_{21}+r_{22}<2 r_{2}$, the probability of cooperation will be correlated negatively with the probability of succeeding in improving the quality and in reducing production time when only one supplier chooses cooperation strategy $\left(\beta^{k}\right)$.

\section{Confirmation is}

$$
\begin{aligned}
\frac{\partial S_{N}}{\partial \beta^{k}} & \\
= & \frac{\left[\rho^{k} d_{1}^{k} n^{k}\left(1+\gamma_{1}^{k}\right)+2 \gamma_{1}^{k} d_{1}^{k} c_{1}^{k}-2\left(1+\gamma_{1}^{k}\right) f_{1}^{k}\right]}{\left[2\left(1+\gamma_{1}^{k}\right)\left(2 \beta^{k}-\rho^{k}\right)^{2} n^{k} d_{1}^{k}\right]} \\
& +\frac{\left[\rho^{k} d_{2}^{k} n^{k}\left(1+\gamma_{2}^{k}\right)+2 \gamma_{2}^{k} d_{2}^{k} c_{2}^{k}-2\left(1+\gamma_{2}^{k}\right) f_{2}^{k}\right]}{\left[2\left(1+\gamma_{2}^{k}\right)\left(2 \beta^{k}-\rho^{k}\right)^{2} n^{k} d_{2}^{k}\right]}
\end{aligned}
$$

$>0$.

This means that the impact of the increase of $\beta^{k}$ on the probability of cooperation is not monotonous. Due to the increase of $\beta^{k}$, the negative impact of noncooperation on profits is decreasing, thereby the suppliers' concerns about risks being reduced. When the expected incentive income of both suppliers choosing to cooperate is higher than a certain degree (twice the extra cost due to cooperation), the increase of $\beta^{k}$ can promote cooperation between suppliers effectively. But when the expected incentive income of both suppliers choosing to cooperate is lower than a certain degree (twice the extra cost due to cooperation), it means that the expected incentive income of both suppliers choosing to cooperate is not high enough to weaken the negative effects of noncooperation on profits (the increase of $\beta^{k}$ ). Meanwhile, the willingness of noncooperation will be significantly increased, resulting in a decline in the probability of cooperation.

\section{An Application}

To aid a further understanding, an application of the model is conducted in this section. The main objective is to explore the cooperation tendency between suppliers in the delivery phase. The data of the parameters setting, as shown in Table 2, are collected from one highway project in Eastern China based on the survey.

4.1. Parameters Setting. Five products in the highway projects are taken as the example. The parameters can be classified into two types, namely, internal parameters and external parameters.

4.1.1. Internal Parameters. The internal parameters are mainly manifested in the elements regarding the suppliers' production capacity, which consist of order quantity $\left(d_{i}^{k}\right)$, unit 
TABLE 2: Parameters setting in the simulation.

\begin{tabular}{lcccccccccccc}
\hline Products $k$ & $d_{1}^{k}$ & $c_{1}^{k}$ & $\gamma_{1}^{k}$ & $f_{1}^{k}$ & $d_{2}^{k}$ & $c_{2}^{k}$ & $\gamma_{2}^{k}$ & $f_{2}^{k}$ & $m^{k}$ & $n^{k}$ & $\rho^{k}$ & $\beta^{k}$ \\
\hline$(1)$ & 1.00 & 0.33 & 0.17 & 0.47 & 0.88 & 0.24 & 0.09 & 0.36 & 3.23 & 1.56 & 0.53 & 0.21 \\
$(2)$ & 0.87 & 0.25 & 0.09 & 0.31 & 0.90 & 0.34 & 0.15 & 0.30 & 4.11 & 1.40 & 0.26 & 0.11 \\
$(3)$ & 0.93 & 0.27 & 0.14 & 0.32 & 0.98 & 0.31 & 0.11 & 0.32 & 3.85 & 1.53 & 0.40 & 0.16 \\
$(4)$ & 1.00 & 0.34 & 0.14 & 0.29 & 0.81 & 0.40 & 0.11 & 0.20 & 4.02 & 1.50 & 0.31 & 0.18 \\
$(5)$ & 0.95 & 0.31 & 0.12 & 0.34 & 1.00 & 0.40 & 0.09 & 0.38 & 3.37 & 1.44 & 0.50 & 0.22 \\
\hline
\end{tabular}

production cost $\left(c_{i}^{k}\right)$, cost externality coefficient $\left(\gamma_{i}^{k}\right)$, and cooperation cost $\left(f_{i}^{k}\right)$.

4.1.2. External Parameters. The external parameters are determined by the interactions between multistakeholders in the market, such as unit price paid by the owner $\left(m^{k}\right)$ and unit incentive price paid by the owner $\left(n^{k}\right)$. The probabilities of success when both suppliers choose to cooperate $\left(\rho^{k}\right)$ or only one supplier chooses to cooperate $\left(\beta^{k}\right)$ are also very important parameters.

The parameters mentioned above are the input data of the model. Besides, there are another two key parameters, $x$ and $y$, which depict the initial cooperation tendency of the system. After setting the initial value of $x$ and $y$, the evolutionary cooperation tendency can be noted clearly by using the replicator dynamic equations (7). The simulation experiments are conducted on the platform of MATLAB R2016b.

4.2. Results Analysis. There are five groups of products needed in the delivery phase. Each kind of supplier is responsible for providing all five kinds of products for the owner. Whether to develop cooperative relationships between suppliers depends on each supplier's production capacity and market parameters for different products.

In this section, five simulation experiments are conducted to explore the evolutionary processes of the five products, as shown in Figures 2, 3, and 4. In these three figures, the solid lines represent the possibility of supplier I taking a cooperative strategy, while the dotted lines represent the cooperation tendency of supplier II selecting a cooperative strategy. The results of the simulation can be divided into three types.

Type 1. In this type, the replicator dynamic systems of the suppliers who provide products 1,3 , and 5 converge to the ESS $(1,1)$ in 200 simulations. These results are consistent with the discussions appearing above in this paper. The scenarios of products 1,3 , and 5 meet the conditions of category 6 ; namely, $2 \beta^{k}-\rho^{k}<0, r_{12}<r_{1}<r_{11}$, and $r_{22}<$ $r_{2}<r_{21}$. However, even with the same initial settings ( $x=$ $0.7, y=0.35$ ), the cooperation tendencies of each system are different. By contrast, the convergence speed of Figure 2(a) is the highest, while the convergence speed of Figure 2(b) is the lowest, and thereby both suppliers agree to cooperate after 180 simulations. It is also worth noting that in Figures 2(a)-2(b) for products 1 and 3, the cooperation tendency of supplier I drops to a certain degree but then rises rapidly and converges to the ESS, whereas, in Figure 2(c), the cooperation tendency of supplier I grows steadily and converges to the ESS after 120 simulations. The main reason is that the revenue of supplier I is not high enough at the beginning, but it improves gradually with supplier II's increasing willingness to cooperate in Figures 2(a)-2(b) for products 1 and 3. Finally, in Figure 2 for products 1,3 , and 5, ESS $(1,1)$ is achieved.

Type 2. In this type, both suppliers who provide product 2 are not willing to cooperate with each other after 200 simulations. Even at the beginning, the initial parameters setting $(x=$ $0.8, y=0.55)$ is relatively higher than the condition in the first type. The scenarios of product 2 meet the conditions of category 1; namely, $r_{1} \geq \max \left(r_{11}, r_{12}\right)$ and $r_{2} \geq \max \left(r_{21}, r_{22}\right)$. Then, the extra costs are too high, and the expected incentive incomes are relatively lower; following that the cooperation tendencies of both suppliers drop sharply and converge to $\operatorname{ESS}(0,0)$ after 60 simulations.

Type 3. In this type, the replicator dynamic system of the suppliers who provide product 4 converges to $\operatorname{ESS}(0,1)$ in 200 simulations. The scenarios of product 4 meet the conditions of category 2 , which are $2 \beta^{k}-\rho^{k} \geq 0, r_{1} \geq \max \left(r_{11}, r_{12}\right)$, and $r_{21}<r_{2}<r_{22}$. Although the initial cooperation tendency setting of supplier I $(x=0.8)$ is relatively higher than the condition in the first type, the extra cost is too high and the expected incentive income is relatively lower so that supplier I is not willing to choose cooperation strategy. On the contrary, for supplier II who provides product 4, although the probability of success is relatively lower when both suppliers choose to cooperate with each other, the expected incentive income is higher than its extra cost. So, supplier II is willing to select cooperation strategy. However, due to the situation that supplier I does not prefer to cooperate with supplier II, the cooperation tendency of supplier II grows slightly. Finally, $\operatorname{ESS}(0,1)$ is achieved.

4.3. Management Insights. Although there are spillover effects on knowledge and technology, the owner of the major projects prefers promoting suppliers to develop stable cooperative relationships so as to improve the product quality, increase productivity, and reduce the production cost. It can be seen from the application that multistakeholders can influence behaviors mutually, while a multiple key factors also affect their behaviors. Therefore, the following recommendations for participated multistakeholders can be drawn, according to the game analysis above during delivery period. 


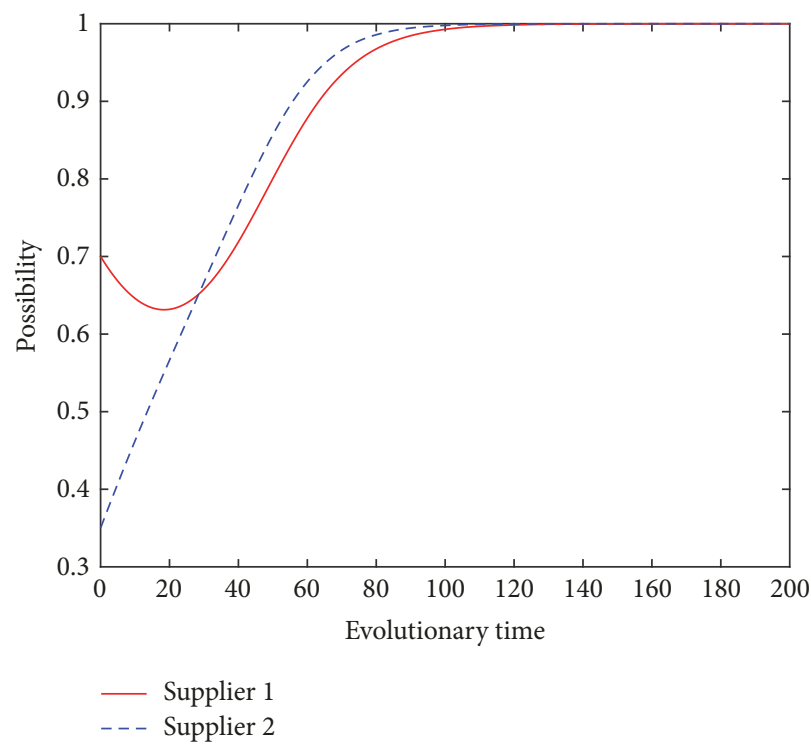

(a)

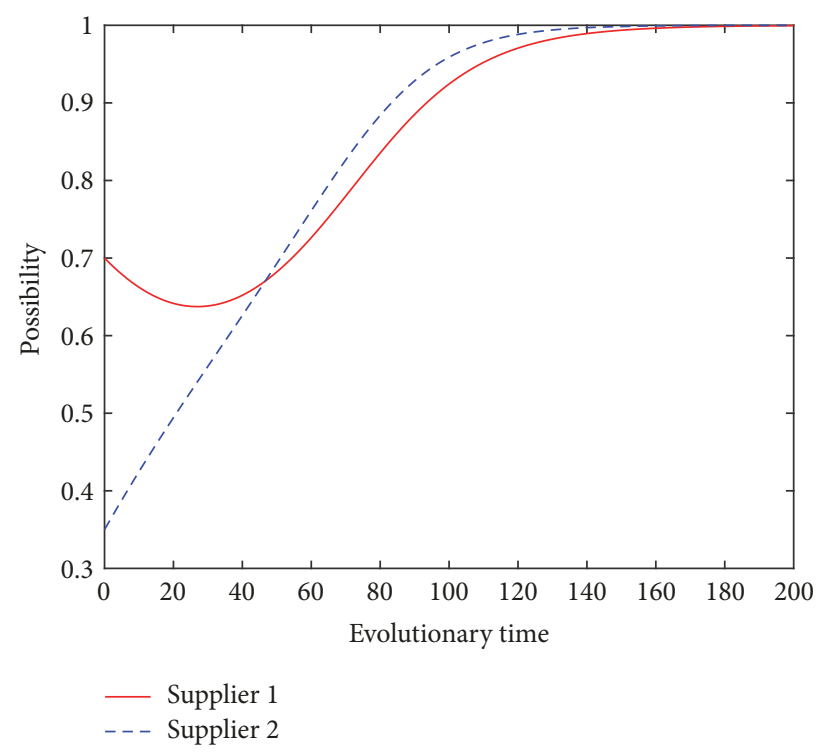

(b)

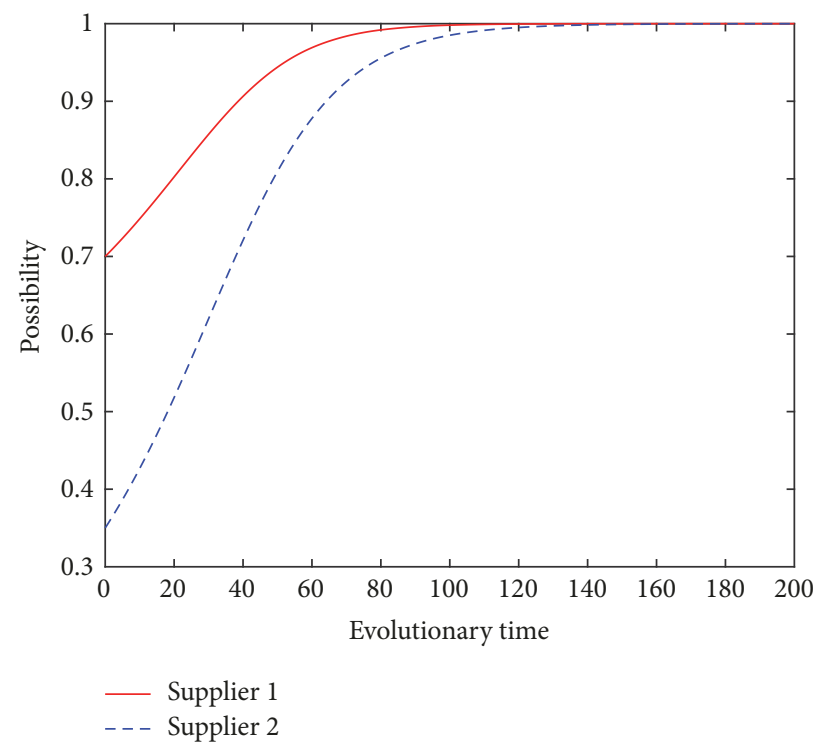

(c)

FIgURE 2: The evolutionary processes of products 1,3 , and 5 .

4.3.1. Recommendations to the Suppliers. Based on the analysis above, higher production quantity, production cost, cost externality coefficient, and the probability of success during cooperation, as well as lower cooperation cost, can promote the suppliers to develop a cooperative relationship with each other. Therefore, for those suppliers who meet the conditions above, the best decision is to try their best to seek for the opportunities to cooperate with other suppliers that provide the same product for the project owner in the industry.

4.3.2. Recommendations to the Owner. The main management sights are mainly manifested in the recommendations for the owner who looks forward to promoting the development of cooperative relationships between suppliers. On one hand, the influencing factors which are directly related to the owner are order quantity $\left(d_{i}^{k}\right)$ and unit incentive price paid by the owner $\left(n^{k}\right)$. The game model has shown that the increased order quantity and unit incentive price can be the force to strengthen the cooperation tendency of suppliers. Therefore, firstly, the larger the order quantity is, the more willing the suppliers are to choose cooperation strategy. Secondly, the owner should pay attention to the incentive mechanism. The higher the incentive intensity is, the more the incentive to achieve cooperation between suppliers will be. The owner should raise the incentive intensity to the supplier. For example, the owner applies a higher price subsidy to the supplier in the contract for the amortization of the automation equipment purchase and the plant construction cost. It aims to realize the incentive to the increase in the 


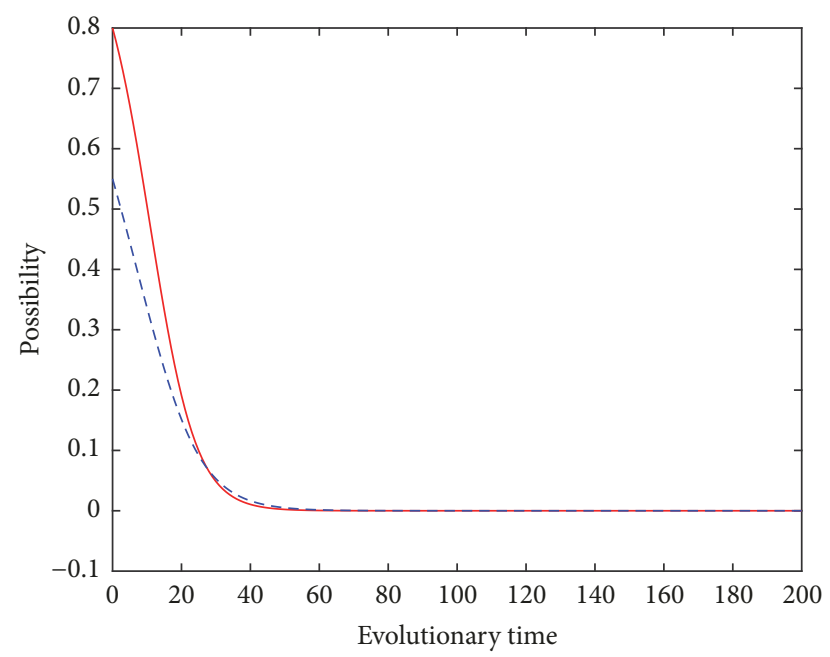

- Supplier 1

- - Supplier 2

FIgURE 3: The evolutionary process of product 2.

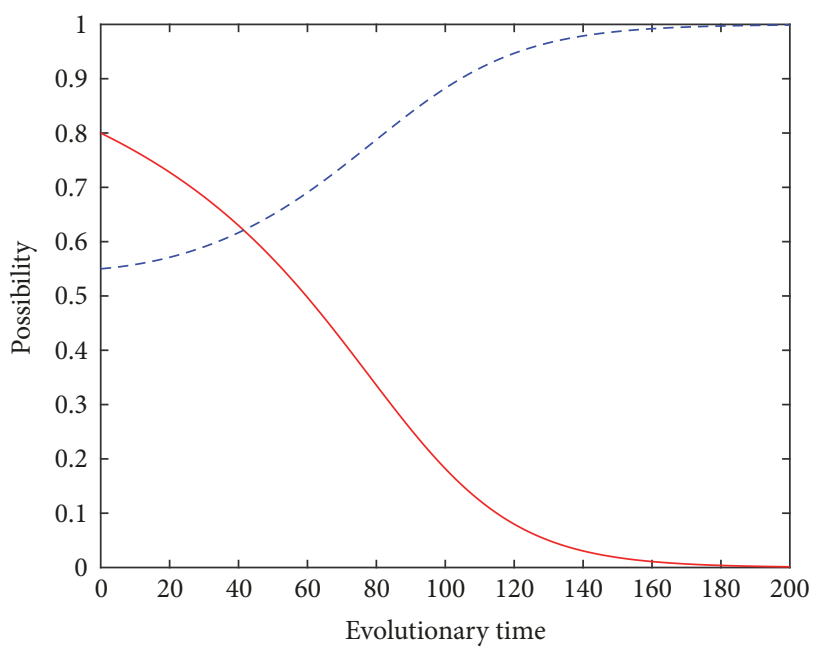

- Supplier 1

- - Supplier 2

FIGURE 4: The evolutionary process of product 4.

supplier's production capacity. Besides, cost sharing incentive mechanism can also be adopted in the contract.

On the other hand, there are several influencing factors which are indirectly related to the owner, such as the probabilities of success $\left(\rho^{k}\right.$ and $\beta^{k}$ ) and cooperation cost $\left(f_{i}^{k}\right)$. Thereby, the supplier development program should be introduced to the major project construction management [45]. In addition to the incentive mechanism mentioned above, there is also a need to strengthen information communications with suppliers. For instance, the owner can set up permanent staff in the suppliers so as to allow suppliers to understand the owner's demands more clearly. Moreover, the owner can provide managerial and technical support for the suppliers and encourage them to carry out technological innovation. Then, the probabilities of success $\left(\rho^{k}\right.$ and $\left.\beta^{k}\right)$ can be increased through the supplier development program, while the cooperation cost can be further reduced. Therefore, the probability of supplier cooperation can be greatly improved.

\section{Conclusions}

The issue of promoting stable cooperation among suppliers has become highly relevant to both academics and practitioners. In order to analyze the cooperation tendency among prefabrication suppliers in major construction projects, this paper builds an evolutionary game model to evaluate the supplier-supplier relationship. The payoff matrix among different kinds of suppliers under different strategies is given and the replicator dynamic system is formulated. Then, fourteen "when-then" type scenarios are concluded. The equilibrium points and local stabilities of each scenario are analyzed as well. The fourteen "when-then" type scenarios can be classified into six different evolutionary tracks. In addition, the critical influencing factors and their impacts on cooperation have been investigated. The probability of cooperation between suppliers is positively correlated with order quantity, unit production cost, spillover effect coefficient, unit incentive price, and the success possibility but negatively with the cooperation cost, while it has no concern with the unit price of the product. To verify the theoretical results, simulation experiments come out with significant results: the suppliers' production capacity, owner-supplier contract, and the owner's incentive mechanism directly influence the cooperation tendency of suppliers. The research also shows that multisuppliers can influence each other's behavior.

Based on the evolutionary game analysis, the important management insights obtained in this research suggest broad practical strategies for cooperation in prefabrication production, including promoting cooperation in the projects with large demand, strengthening the incentive mechanism construction, and introducing supplier development program.

This study can help the owner to promote developing cooperative relationships between suppliers in major construction projects. There are also some limitations that should be investigated in the future work, such as the fair preference of each player and the collusion behaviors' influence. These elements would have great influences over the cooperation tendency among suppliers. Taking these elements into consideration can help this research look more close to the reality and help the practitioners improve their understanding of cooperation. These will be studied in future work.

\section{Conflicts of Interest}

The authors declare that there are no conflicts of interest regarding the publication of this paper.

\section{Acknowledgments}

This work was supported by Major Program of National Natural Science Foundation of China (71390521, 71390520), National Natural Science Foundation of China (71571098, 
71732003, 71671088, 71671078, and 71501084), Nanjing University Innovation and Creative Program for Ph.D. Candidate (2016010), and the Program B for Outstanding Ph.D. Candidate of Nanjing University (201701B009, 201701B010).

\section{References}

[1] M. Ouyang, "A mathematical framework to optimize resilience of interdependent critical infrastructure systems under spatially localized attacks," European Journal of Operational Research, vol. 262, no. 3, pp. 1072-1084, 2017.

[2] D. J. Ryan, "Engineering sustainable critical infrastructures," International Journal of Critical Infrastructure Protection, vol. 17, pp. 28-29, 2017.

[3] L. Varga, T. Grubic, P. Greening, S. Varga, F. Camci, and T. Dolan, "Characterizing conversion points and complex infrastructure systems: Creating a system representation for agentbased modeling," Complexity, vol. 19, no. 6, pp. 30-43, 2014.

[4] M. M. Rahman, "Barriers of implementing modern methods of construction," Journal of Management in Engineering, vol. 30, no. 1, pp. 69-77, 2014.

[5] H. Said, "Prefabrication Best Practices and Improvement Opportunities for Electrical Construction," Journal of Construction Engineering and Management, vol. 141, no. 12, Article ID 04015045, 2015.

[6] J. Chai, C. Wu, C. Zhao et al., "Reference tag supported RFID tracking using robust support vector regression and Kalman filter," Advanced Engineering Informatics, vol. 32, pp. 1-10, 2017.

[7] McGraw-Hill, Prefabrication and modularization: Increasing productivity in the construction industry, Smart Market Report, Prefabrication and modularization, Increasing productivity in the construction industry, 2011.

[8] J. T. O'Connor, W. J. O’Brien, and J. O. Choi, “Critical success factors and enablers for optimum and maximum industrial modularization," Journal of Construction Engineering and Management, vol. 140, no. 6, Article ID 4014012, 2014.

[9] D. G. Harper and L. E. Bernold, "Success of supplier alliances for capital projects," Journal of Construction Engineering and Management, vol. 131, no. 9, pp. 979-985, 2005.

[10] J. G. Jeong, M. Hastak, M. Syal, and T. Hong, "Framework of manufacturer and supplier relationship in the manufactured housing industry," Journal of Management in Engineering, vol. 29, no. 4, pp. 369-381, 2013.

[11] L. E. Bygballe, M. Jahre, and A. Swärd, "Partnering relationships in construction: A literature review," Journal of Purchasing and Supply Management, vol. 16, no. 4, pp. 239-253, 2010.

[12] R. Sariola and M. Martinsuo, "Enhancing the supplier's noncontractual project relationships with designers," International Journal of Project Management, vol. 34, no. 6, pp. 923-936, 2016.

[13] H. Håkansson and M. Ingemansson, "Industrial renewal within the construction network," Construction Management and Economics, vol. 31, no. 1, pp. 40-61, 2013.

[14] Y. Xu, B. Yu, Y. Wang, and Y. Chen, "A stochastic evolutionary game perspective on the stability of strategic alliances against external opportunism," Journal of Systems Science \& Complexity, vol. 28, no. 4, pp. 978-996, 2015.

[15] P. Ji, X. Ma, and G. Li, "Developing green purchasing relationships for the manufacturing industry: an evolutionary game theory perspective," International Journal of Production Economics, vol. 166, pp. 155-162, 2015.
[16] M. Motta, Competition Policy: Theory and Practice, Cambridge University Press, 2004.

[17] S. O. Cheung and L. Shen, "Concentration Analysis to Measure Competition in Megaprojects," Journal of Management in Engineering, vol. 33, no. 1, Article ID 04016023, 2017.

[18] J.-Y. Chen, D. M.-H. Chiang, and R.-S. Guo, "Partner selection model for design chain collaboration," International Journal of Production Research, vol. 51, no. 4, pp. 1131-1145, 2013.

[19] S. Lu and G. Hao, "The influence of owner power in fostering contractor cooperation: evidence from China," International Journal of Project Management, vol. 31, no. 4, pp. 522-531, 2013.

[20] Z. Quanji, S. Zhang, and Y. Wang, "Contractual Governance Effects on Cooperation in Construction Projects: Multifunctional Approach," Journal of Professional Issues in Engineering Education and Practice, vol. 143, no. 3, Article ID 04016025, 2017.

[21] A. M. Anvuur and M. M. Kumaraswamy, "Measurement and Antecedents of Cooperation in Construction," Journal of Construction Engineering and Management, vol. 138, no. 7, pp. 797810, 2011.

[22] B. J. Gibson, S. M. Rutner, and S. B. Keller, "Shipper-carrier partnership issues, rankings and satisfaction," International Journal of Physical Distribution and Logistics Management, vol. 32, no. 8, pp. 669-681, 2002.

[23] F. Cruijssen, W. Dullaert, and H. Fleuren, "Horizontal cooperation in transport and logistics: A literature review," Transportation Journal, vol. 46, no. 3, pp. 22-39, 2007.

[24] J. Bemelmans, H. Voordijk, and B. Vos, "Supplier-contractor collaboration in the construction industry:A taxonomic approach to the literature of the 2000-2009 decade," Engineering, Construction and Architectural Management, vol. 19, no. 4, pp. 342-368, 2012.

[25] S. O. Cheung, T. W. Yiu, and O. K. Chiu, "The aggressivecooperative drivers of construction contracting," International Journal of Project Management, vol. 27, no. 7, pp. 727-735, 2009.

[26] A. Paulraj, A. A. Lado, and I. J. Chen, "Inter-organizational communication as a relational competency: Antecedents and performance outcomes in collaborative buyer-supplier relationships," Journal of Operations Management, vol. 26, no. 1, pp. 4564, 2008.

[27] S.-H. Kim and S. Netessine, "Collaborative cost reduction and component procurement under information asymmetry," Management Science, vol. 59, no. 1, pp. 189-206, 2013.

[28] M. Zineldin and T. Bredenlöw, "Strategic alliance: Synergies and challenges: A case of strategic outsourcing relationship "SOUR", International Journal of Physical Distribution and Logistics Management, vol. 33, no. 5, pp. 449-464, 2003.

[29] B. Jiang, S. Talluri, and T. Yao, "Improving supplier's situation through supplier cooperation: the case of Xintang jeans town," International Journal of Production Economics, vol. 139, no. 2, pp. 431-437, 2012.

[30] T. Y. Choi, Z. Wu, L. Ellram, and B. R. Koka, "Suppliersupplier relationships and their implications for buyer-supplier relationships," IEEE Transactions on Engineering Management, vol. 49, no. 2, pp. 119-130, 2002.

[31] Z. Wu, T. Y. Choi, and M. J. Rungtusanatham, "Supplier-supplier relationships in buyer-supplier-supplier triads: Implications for supplier performance," Journal of Operations Management, vol. 28, no. 2, pp. 115-123, 2010.

[32] M. Saad, M. Jones, and P. James, "A review of the progress towards the adoption of supply chain management (SCM) relationships in construction," European Journal of Purchasing and Supply Management, vol. 8, no. 3, pp. 173-183, 2002. 
[33] Y. Hong and J. L. Hartley, "Managing the supplier-supplier interface in product development: The moderating role of technological newness," Journal of Supply Chain Management, vol. 47, no. 3, pp. 43-62, 2011.

[34] S. G. Lazzarini, D. P. Claro, and L. F. Mesquita, "Buyer-supplier and supplier-supplier alliances: Do they reinforce or undermine one another?" Journal of Management Studies, vol. 45, no. 3, pp. 561-584, 2008.

[35] M. Bresnen, "Deconstructing partnering in project-based organisation: Seven pillars, seven paradoxes and seven deadly sins," International Journal of Project Management, vol. 25, no. 4, pp. 365-374, 2007.

[36] O. Pesämaa, P. E. Eriksson, and J. F. Hair, "Validating a model of cooperative procurement in the construction industry," International Journal of Project Management, vol. 27, no. 6, pp. 552-559, 2009.

[37] M. Nagarajan and G. Sošić, "Coalition stability in assembly models," Operations Research, vol. 57, no. 1, pp. 131-145, 2009.

[38] D. Granot and S. Yin, "Competition and cooperation in decentralized push and pull assembly systems," Management Science, vol. 54, no. 4, pp. 733-747, 2008.

[39] J. Liu, K. L. Teo, X. Wang, and C. Wu, "An exact penalty function-based differential search algorithm for constrained global optimization," Soft Computing, vol. 20, no. 4, pp. 13051313, 2016.

[40] J. W. Weibull, Evolutionary Game Theory, The MIT Press, Cambridge, Mass, USA, 1997.

[41] J. Liu, R. Gao, C. Y. J. Cheah, and J. Luo, "Evolutionary game of investors' opportunistic behaviour during the operational period in PPP projects," Construction Management and Economics, vol. 35, no. 3, pp. 137-153, 2017.

[42] T. Feng, S. Tai, C. Sun, and Q. Man, "Study on cooperative mechanism of prefabricated producers based on evolutionary game theory," Mathematical Problems in Engineering, vol. 2017, Article ID 1676045, 6 pages, 2017.

[43] D. Friedman, "Evolutionary games in economics," Econometrica: Journal of the Econometric Society, vol. 59, no. 3, pp. 637666, 1991.

[44] T. Xiao and G. Yu, "Supply chain disruption management and evolutionarily stable strategies of retailers in the quantitysetting duopoly situation with homogeneous goods," European Journal of Operational Research, vol. 173, no. 2, pp. 648-668, 2006.

[45] C. Bai and J. Sarkis, "Supplier development investment strategies: a game theoretic evaluation," Annals of Operations Research, vol. 240, no. 2, pp. 583-615, 2016. 


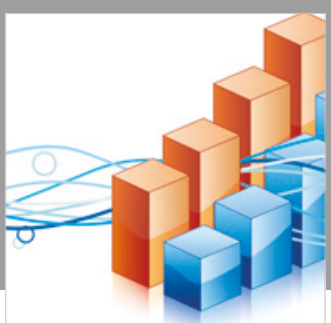

Advances in

Operations Research

\section{-n-m}
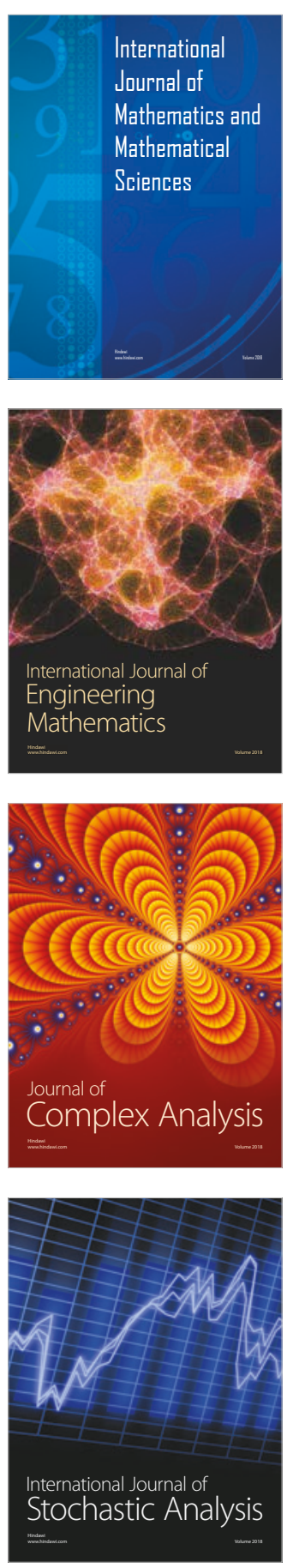
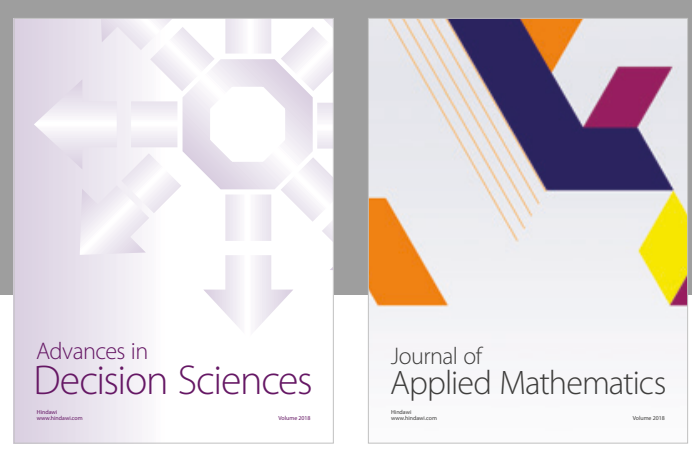

Journal of

Applied Mathematics
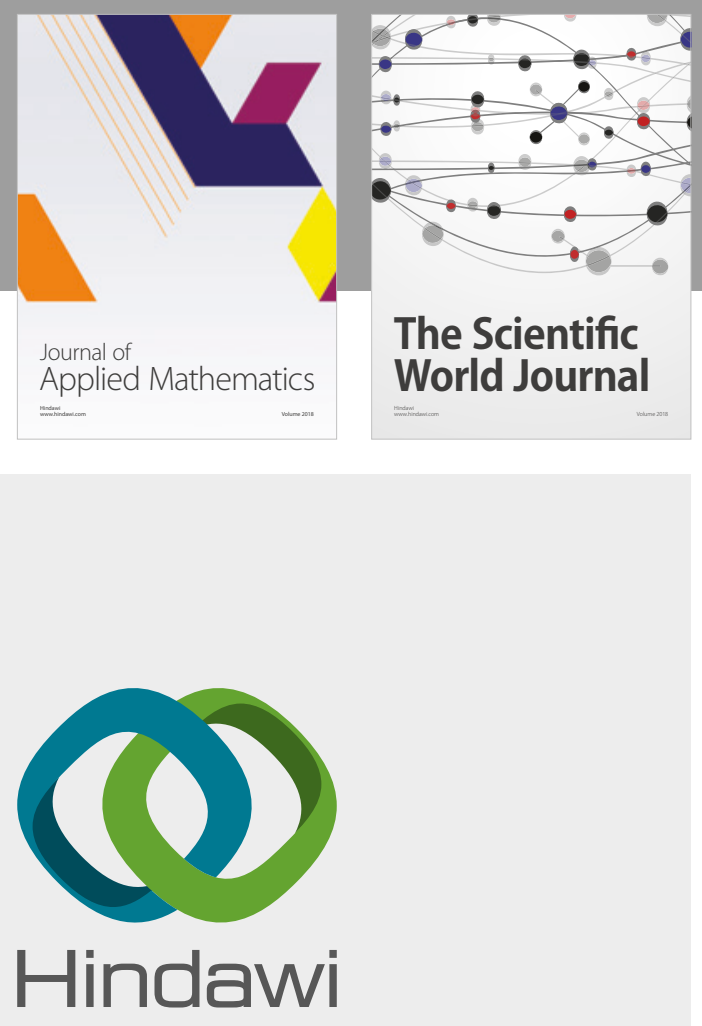

Submit your manuscripts at

www.hindawi.com

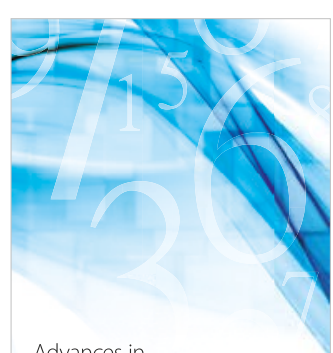

Advances in
Numerical Analysis
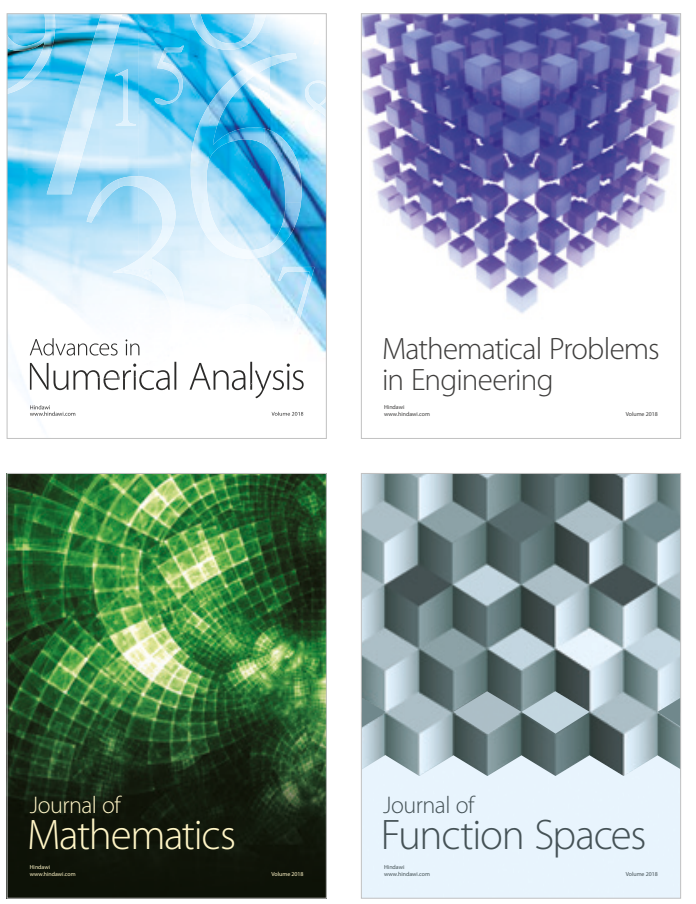

Mathematical Problems in Engineering

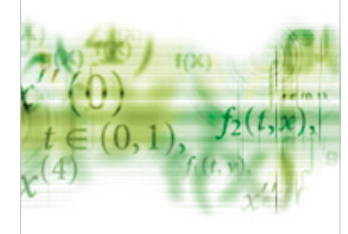

International Journal of

Differential Equations

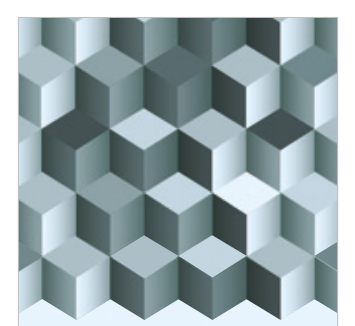

Journal of

Function Spaces
The Scientific

World Journal

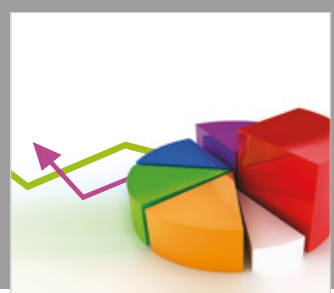

Journal of

Probability and Statistics
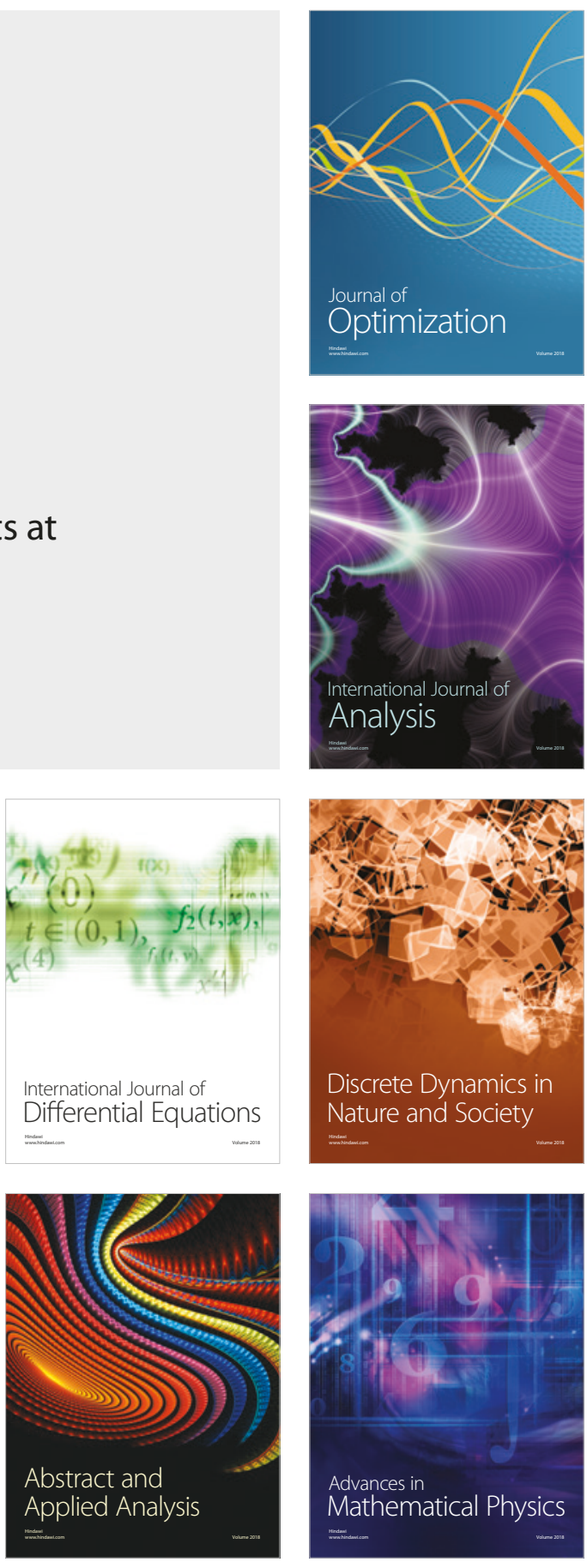